Jia Li*, Ping Xie, Bin Ai and Lisheng Li

\title{
Multilingual communication experiences of international students during the COVID-19 Pandemic
}

https://doi.org/10.1515/multi-2020-0116

\begin{abstract}
While an increasing literature on multilingualism addresses the key role of language in access to social resources, including crisis communication, little attention has been paid to practices of English-mediated multilingualism. Based on semi-structured interviews with 10 international students from South Asia and Southeast Asia receiving their higher education in China, the study reveals what language-related challenges international students encounter, how they mobilize their multilingual resources to enhance their access to crisis communication and build a shared community, and how their multilingual competences are valorized and enacted in the shifting paradigm of the China-oriented new economy addressing mutual accountability in South-South cooperation. The study suggests that English-mediated multilingualism in China fails to bridge the needs of international students of diverse backgrounds. The study also calls attention to the shifting paradigm of multilingual studies and the necessity of addressing the real world problems of health communication in a diverse context.
\end{abstract}

Keywords: multilingualism, China's Belt and Road Initiative, English as a global language, COVID-19 crisis communication

\section{Introduction}

Multilingualism in China's public sphere came into the spotlight shortly after the coronavirus was officially confirmed on 20th of January, 2020 (Li, Jia 2020). Up until then, English had been the unquestioned language of international communication in China. The active mobilization of non-English foreign language

\footnotetext{
*Corresponding author: Jia Li, Yunnan University, Kunming, China, E-mail: jia_li_yunnan@qq.com. https://orcid.org/0000-0002-3391-5720

Ping Xie: Yunnan University, Kunming, China

Bin Ai: Shanghai University of Finance and Economics, Shanghai, China

Lisheng Li: Yunnan Normal University, Kunming, China, E-mail: jia_li_yunnan@qq.com
} 
resources that has rapidly been gathering pace since then indicates the new profile of China's economic, demographic and sociolinguistic structure. Since China became the world's second largest economy in 2011, China's economic power and its growing domestic market have played a pivotal role as a hub for regional trade growth and economic integration in Asia and Africa (Li, Xing 2019). As part of its socioeconomic rise, China has emerged from the largest sending country of international students to also become the third largest receiving country (Study International Staff 2018). By 2018, the total number of international students receiving their higher education in China was almost 500,000 and over 70 percent of them were from Asia and Africa (Ministry of Education 2019). The distribution of international students in China also highlights the geopolitical strategy of positioning China's border provinces as "windows" to neighbouring countries. In Yunnan province in China's southwest, for example, over 80 percent of international students are from Southeast Asia and South Asia (Yun and Zhu 2017).

In addition to the increasing number of international students of diverse linguistic backgrounds, non-English foreign language programs are gaining in importance in China. In 2017, 583 Chinese universities offered 1,417 foreign language programs at undergraduate levels and these foreign languages are predominantly the national languages of China's neighbouring countries (Han et al. 2019). The increasing number and scale of non-English foreign language programs is unprecedented and largely geopolitically motivated. Yunnan University, for instance, has established 10 foreign language degree programs in languages of Southeast Asia and South Asia within only seven years (Li, Jia 2020). The increasing importance of establishing non-English foreign languages is embedded in the reciprocal approach of China's foreign diplomacy towards peripheral countries, especially those in the list of China's Belt and Road Initiative (B\&R) (Paradise 2019; Qin 2014).

Despite the recent emergence of a high level of attention to non-English foreign languages, English is still the most dominant foreign language in China (Zhang, In preparation). English is not only a key enabler for Chinese students' academic success and employability (Pan 2015), but is often conceived as a link language to attract international students coming to China for higher education (Kuroda 2014), facilitate international students' Chinese language learning and solve their intercultural communication problems in China (Duan 2020). However, given the substantial number of international students arriving from non-English speaking countries, English as an imagined communication medium has been thrown into question. One of the problems with English-mediated communication is that not all international students in China are proficient in English, while also lacking Chinese proficiency (Li, Jia 2020). Over the course of the COVID-19 crisis, 
the tensions related to the use of English as a link language for international students have become more prominent, as access to public health information in China is, by and large, mediated by Chinese and English.

Against this background, this study aims to investigate two questions: (1) How do international students draw on their linguistic resources to navigate access to public health information? (2) How are their multilingual experiences embedded in the shifting paradigm of the world's political economy and China's global expansion?

\section{English-mediated multilingualism}

In China, Putonghua is considered the exclusive national language and English is imagined as the solution to any intercultural communication problems that might arise from this. We call this linguistic situation English-mediated multilingualism. Here, we use it to understand how international students negotiate access to public health communication during the COVID-19 crisis. English-mediated multilingualism is not unique to China. In many non-English speaking countries, Englishmediated multilingualism is so dominant that it is rarely challenged but widely assumed to be the only legitimate and most equitable form of embracing linguistic diversity. The practices of English-mediated multilingualism in educational settings can be manifested in legitimizing English as elite form of multilingualism (Martín Rojo 2010; Preece 2019), naturalizing English as medium of instruction to increase individual competitiveness (Piller and Cho 2013; van der Walt 2013), and accepting English as source of authority and an index of academic excellence and global accountability (Phillipson 2008; Piller 2016b, 2019).

These English-centric ways of seeing multilingualism have resulted in many negative social consequences in non-English speaking countries in that people who are not proficient in this form of multilingualism - the national language and English - are deprived of access to social resources (Han 2013; Piller and Cho 2013; van der Walt 2013). Rather than contributing to the common good and global justice, English-mediated multilingualism has entrenched social inequality by erasing diversity and paying tribute to the Anglophone center (Piller 2016a, 2016b). Given the increasing number of international students migrating from non-English speaking countries to China, English alone is far from being an effective medium of crisis communications, a fact highlighted by the COVID-19 pandemic. Therefore, it is urgent to understand the real linguistic needs of international students to combat the global crisis and call attention to new ways of seeing multilingualism in the context of the shifting paradigm of China-oriented internationalization that focuses on South-South cooperation. 


\section{Methodology}

In order to gain a nuanced understanding of international students' experiences with public health communication during the COVID-19 pandemic, we interviewed 10 participants receiving their higher education in Yunnan. Table 1 provides an overview of the participants (the order of their language backgrounds is based on the range of their self-identified language proficiency).

At the time of collecting data for this study in April 2020, some of our participants (P2, P3, P4, P5, P7) had stayed in China throughout the epidemic there, some had gone back to their home country for holidays just before the outbreak (P6, P8, $\mathrm{P} 9, \mathrm{P} 10)$, and P1 returned to Bangladesh during the outbreak. We employed semistructured interviews, either online or face-to-face, to gain an understanding of their lived experiences during the COVID-19 pandemic from late January to the end of April. Interviews were conducted in either English or Chinese or mixing both languages depending on the preference of our participants. The transcripts of the audio-recorded interviews were analyzed using content analysis (Krippendorff and Bock 2009) to map out their reported language use during the crisis.

\section{Findings}

The description below is based on how our participants reported using different languages for their access to crisis communication over the course of the COVID-19 pandemic. The analysis of language practices will be anchored in specific interactions and social circumstances, and the limitations of each linguistic repertoire will be discussed.

Table 1: Overview of research participants.

\begin{tabular}{llrll}
\hline Code & Gender & Age & Country of origin & Self-identified language backgrounds \\
\hline P1 & F & 19 & Bangladesh & Bangla, English, Hindi \\
P2 & M & 18 & Bangladesh & Bangla, Hindi \\
P3 & M & 27 & Bangladesh & Bangla, English, Chinese, Arabic, Hindi \\
P4 & M & 24 & Pakistan & Urdu, English, Punjabi, Hindi \\
P5 & M & 29 & Nepal & Nepali, English, Hindi, Chinese \\
P6 & F & 21 & Thailand & Thai, Chinese \\
P7 & F & 28 & Vietnam & Vietnamese, Chinese \\
P8 & M & 29 & Myanmar & Chinese, Burmese \\
P9 & F & 21 & Cambodia & Khmer, Chinese \\
P10 & F & 20 & Laos & Laotian, Thai, Chinese \\
\hline
\end{tabular}




\subsection{Overcoming limited Chinese proficiency through translation and interpreting}

Putonghua constitutes the major medium of public health communication throughout China. However not all of our participants (P1, P2, P4) are able to speak Chinese and many of them (P5, P6, P7, P10) admit that their proficiency is insufficient to fully understand media reports or relevant regulations and policies in Chinese. Participants reported dealing with these language barriers in two ways. First, they looked for language brokers such as relatives or co-nationals working and living in China. Others turned to their Chinese classmates or friends for information and clarification. Second, they relied on various translation apps on their smartphones for help.

In fact, all of our participants admit that the use of translation apps is an important part of their lifestyle in China. Apart from checking different Chinese news reports online, their access to professional Chinese knowledge and daily communication is often facilitated by translation apps such as those on WeChat and Baidu. Both WeChat and Baidu were unanimously declared as the most convenient apps in China. WeChat, in particular, is an indispensable accessory and is used for multi-purpose messaging with Chinese teachers, friends, and business partners, it is linked to China's payment system, and required for ordering transport and other services, or for getting registered as a member of social organizations. Baidu is the dominant Internet search engine, similar to Google. Both WeChat and Baidu can not only transcribe and translate but also include an AI-powered language translator capable of image-scanning and real time audio translation.

The experience of $\mathrm{P} 5$ illustrates the importance of using translation software for Chinese-centered professional health communication. Having passed HSK-5 (Hanyu Shuiping Kaoshi, the standard Chinese proficiency test-Band 5), P5 was called upon by one of his Nepalese friends, who did not even have survival Chinese proficiency, to accompany him to hospital and interpret for him during his medical examination. However, P5's Chinese language proficiency reached its limits when it came to the translation of medical reports. He then turned to Baidu, scanned the Chinese reports, and sent the English version back to his friend's family in Nepal.

Despite offering translation service for hundreds of languages, smartphone apps like Baidu do not eliminate the language barrier entirely given that the advanced functions such as scanning and simultaneous interpretation are only available in certain popular languages. There is no scanning function for South Asian languages available on WeChat and Baidu, and only two Southeast Asian languages are being developed at the time of this study. In contrast, English is the default language embedded in Chinese automated translation tools. Therefore, P5 
and his friend's family still had to rely on English, a language in which they are not particularly proficient, either, to make sense of the Chinese medical reports.Therefore, those who lack Chinese proficiency and whose national languages are not included in the existing AI-functions will not be able to turn to free access to advanced translation resources if their English proficiency is insufficient.

\subsection{English as imagined solution to communication barriers}

As shown in the previous section, English is the default language for international communication embedded in translation apps. Furthermore, English is also the imagined communication medium for international students' access to educational resources during the COVID-19 crisis. However, limited English proficiency caused considerable barriers for international students.

One of the barriers is the shifting language medium from Chinese to English. P10 and her international classmates were second year undergraduates studying a Chinese-medium degree program in International Business and Economics. However, in early March they were informed that the Advanced Mathematics course would be taught in English instead of Chinese with the following justification:

老师说这门课很难, 是网课, 怕我们难理解, 就用英语来上。

Our (Chinese) teacher explained that this course was very challenging. It was even more challenging to have online class, so the teacher decided to use English to teach the course (Interview with P10)

Changing the medium of instruction seem to have been based on the assumption that international students like P10 would have higher levels of language proficiency in English than in Chinese. The measure was meant to support students' learning and to overcome anticipated comprehension problems resulting from online instruction required to minimize the spread of COVID-19.

While well-meant, the switch from Chinese to English created significant problems for P10, whose English proficiency is low. She reported that she could not understand her Chinese teacher's English and the content knowledge delivered in English. Within less than two months, many of her classmates stopped turning up online. P10 was quite frustrated by the time of the interview and what worried her most was how to pass the final exam in this particular class.

In order to help her understand the English-mediated class content, P10 turned to Thai-mediated translation apps for help. According to P10, the Laotian language is very similar to the Thai language both in speech and in script. Her 
exposure to Thai social media from a young age had developed her receptive multilingual competence in Thai. Like other participants confronting their disadvantages in English and Chinese, she creatively mobilized her grassroots multilingual repertoires to help her navigate the COVID-19 crisis.

\subsection{Contributing to the fight against COVID-19 through languages other than Chinese and English}

While Chinese and English predominate, other languages are increasingly valorized in China. For instance, from early March, an increasing number of non-English foreign languages became available online for foreigners' access to the key messages on combating the COVID-19 pandemic (Li, Yuming 2020). Beyond state efforts, our interviews reveal how other languages may become powerful resources to contribute to the fight against COVID-19, initially within China and later globally.

P8 provides an example. A bilingual ethnic Chinese from Myanmar who is highly proficient in both Chinese and Burmese, $\mathrm{P} 8$ made use of his linguistic and social resources to help donate 50,000 masks to Wuhan in early February when medical supplies were badly needed there (see also Zhang and Wu, this issue). P8's identity as the chairman of the international students' association at his university had helped him build his social networks with his peers, and working as a parttime interpreter for Chinese business people had also extended his social and economic resources. When COVID-19 struck, P8's Chinese friends turned to him asking him to look for medical masks so that they could purchase and donate masks to Wuhan. P8 mobilized his connections with Myanmar and other Southeast Asian countries to look for medical resources, at a time when COVID-19 was not yet serious there. Through his multilingual and transnational networks he found a factory in Thailand, which could provide 50,000 medical masks. These were transported to Kunming by direct flight from Bangkok and from there donated to Wuhan.

Similar to P8, P3's multilingual repertoires made him a source of authority for his Bangladeshi country mates in China. P3 used to study the Arabic language with four years of professional training in interpreting the Quran at Dhaka University before moving to China to learn Chinese in 2017. Confronted with the negative media reports in English and Bangla at the outset of the pandemic and the lack of sufficient information in Chinese reports on what was going on, P3 turned to the Quran for relevant verses and circulated them in Arabic and Bangla among his social networks as a justification for quarantine orders and the lockdown of Wuhan. In the interview, P3 expressed his trust in the Chinese government by quoting religious verses: 
Chinese government is doing right (in the lockdown of Wuhan). Allah's Messenger already said 1500 years ago that 'If you hear that it (plague) has broken out in a land, do not go to it; but if it breaks out in a land where you are present, do not go out escaping from it', so it is correct to stay in China (not going back to Bangladesh), and for Wuhan people staying in Wuhan.

Apart from offering updates and comforting messages, and persuading his country mates to believe in China, P3 also mobilized his social and business networks to deliver medical products needed by Chinese people and the people of the world. In early February, P3 imported 15,000 masks from the Middle East and sold them to his Chinese teachers and Chinese business partners when there was a severe shortage of masks in China. P3 did not engage in any price gouging: out of the 3.5 yuan for which he sold each mask, he made 1 yuan as profit. That his Chinese teachers could go out to do shopping with sufficient masks made P3 feel a great sense of achievement. His satisfaction was further enhanced by the fact that the unexpected profit allowed him to purchase a washing machine for his mother in Bangladesh. P3's networks in the Middle East, which enabled this success, result from his previous business translation experiences with Arabic speakers in Yiwu, the world largest wholesale market (Ma 2020).

By the time we interviewed P3 on 10th of April, P3 had been shifting gears and was looking for a large number of 3M masks and $\mathrm{N} 95$ masks to be delivered to the USA from China. Although he does not have American contacts, his Pakistani friend has. In yet another twist of grassroots multilingualism, P3 and his Pakistani communicate in Urdu, a language P3 is familiar with due to its similarity with Hindi, the language of Bollywood. During the COVID-19 pandemic, P3 has successfully mobilized his multilingual competences and his cultural, social and business networks to contribute to the global fight against the disease.

The multilingual communication experiences of P3 and P8 show that foreign languages other than English constitute powerful links in global supply chains and transnational networks. The value of these multilingual competences largely depends on Chinese proficiency as the link language enabling their participation and facilitating their mobilization of other social resources across time and space.

\section{Discussion and conclusion}

In this study we have examined the multilingual communication experiences of South Asian and Southeast Asian students of diverse linguistic backgrounds over the course of the early months of the COVID-19 pandemic in China. Our findings demonstrate that their Chinese proficiency is, by and large, insufficient to meet their crisis communication needs and they need to turn to brokering and 
particularly translation apps. The utility of these, however, is limited due to their English-centric nature.

The multilingual communication experiences of international students have thrown the long-established value of English as global lingua franca into question. The fallacy of English in China as the best media for intercultural health communication and knowledge production has caused unintended consequences. The availability of many translation apps does not necessarily enhance access to health communication for international students with limited English and Chinese proficiency. On the contrary, the advanced digital communication technologies only serve to privilege those speaking English and Chinese but marginalize speakers of other languages. The same is true where English in China is imagined as ideal medium of communication between Chinese teachers and international students.

Beyond English, the valorization of diverse multilingual repertoires may offer alternative paths to building solidarity to comfort each other (P3), delivering medical supplies and connecting China with Southeast Asia (P8), and contributing to the global relief effort and mobilizing regional business networks (P3).

The new valorization of small languages which we have shown here has been nascent in China for some time but has been accelerated by the pandemic. This new multilingualism is embedded in the shifting paradigm of the China-oriented new economy addressing the mutual accountability in South-South cooperation. China's approach to global governance such as the recent B\&R has generated a new paradigm for the world order under China's leadership (Li, Xing 2019). As part of the people-to-people connection project in China's B\&R, languages of peripheral countries are also included to bridge the understanding between China and the world. It is noted that China-oriented multilingualism is not just a replacement of English-mediated multilingualism but something qualitatively different. Chinesemediated multilingualism can be conceptualized as the bi-directional approach in valorizing both Chinese and the national languages of non-English speaking countries where China's global market can reach. Over the COVID-19 pandemic, the multilingual competences in both Chinese and national languages provide international students like P3 and P8 with access to social and business resources, which served to enhance their entrepreneurial subjectivities and sense of global responsibility.

Finally, to escape the self-fulfilling prophecy of English-mediated knowledge production and to raise the authority of grassroots voices to combat the COVID-19 crisis, we suggest an epistemological shift from the global north to the global south where multilingual realities form thousands of years of history and civilization, and where indigenous knowledge constitutes the essence of guiding principles embedded in social practice (see also Chen 2020, this issue). 


\section{References}

Chen, Xi. 2020. Fighting COVID-19 in East Asia: The role of classical Chinese poetry. Multilingua 39(5). 565-576.

Duan, Wei. 2020. Can Chinese language learning reinforce English supremacy? In Language on the move. Available at: https://www.languageonthemove.com/can-chinese-language-learningreinforce-english-supremacy/.

Han, Huamei. 2013. Individual grassroots multilingualism in Africa Town in Guangzhou: The role of states in Globalization. International Multilingual Research Journal 7(1). 83-97.

Han, Yawen, Xuesong Gao \& Jinyuan Xia. 2019. Problematising recent developments in nonEnglish foreign language education in Chinese universities. Journal of Multilingual and Multicultural Development 40(7). 562-575.

Kuroda, Chiharu. 2014. The new sphere of international student education in Chinese higher education: A focus on English-medium degree programs. Journal of Studies in International Education 18(5). 445-462.

Krippendorff, Klaus \& Mary Bock. 2009. The content analysis reader. Los Angeles: SAGE Publications, Inc.

$\mathrm{Li}$, Jia. 2020. Coronavirus meets linguistic diversity. In Language on the move. Available at: https://www.languageonthemove.com/coronavirus-meets-linguistic-diversity/.

Li, Xing. 2019. Mapping China's 'One Belt One Road' initiative. Switzerland: Palgrave Macmillan.

$\mathrm{Li}$, Yuming. 2020. Language lessons of COVID-19 and linguistic disaster preparedness. In Language on the move. Available at: https://www.languageonthemove.com/languagelessons-of-covid-19-and-linguistic-disaster-preparedness/.

Ma, Yuanmeng. 2020. Empowerment of Chinese Muslim women through Arabic? In Language on the move. Available at: https://www.languageonthemove.com/empowerment-of-chinesemuslim-women-through-arabic/.

Martín Rojo, Luisa. 2010. Constructing inequality in multilingual classrooms. Berlin: Walter De Gruyter.

Ministry of Education. 2019. 2018年来华留学统计 [The statistical information of study abroad students in China in 2018]. Available at: https://www.moe.gov.cn/jyb_xwfb/gzdt_gzdt/ s5987/201904/t20190412_377692.html.

Pan, Lin. 2015. English as a global language in China: Deconstructing the ideological discourses of English in Language Education. London: Springer.

Paradise, James F. 2019. China's quest for global economic governance reform. Journal of Chinese Political Science 24(3). 471-493.

Phillipson, Robert. 2008. The linguistic imperialism of neoliberal empire. Critical Inquiry in Language Studies 5(1). 1-43.

Piller, Ingrid. 2016a. Monolingual ways of seeing multilingualism. Journal of Multicultural Discourse 11(1). 25-33.

Piller, Ingrid. 2016b. Linguistic diversity and social justice. Oxford: Oxford University Press.

Piller, Ingrid. 2019. On the conditions of authority in academic publics. Journal of Socio Linguistics 23(5). 521-528.

Piller, Ingrid \& Jean Cho. 2013. Neoliberalism as language policy. Language in Society 42(1). 23-44.

Piller, Ingrid \& Loy Lising. 2014. Language, employment and settlement: Temporary meat workers in Australia. Multilingua 33(1/2). 35-59. 
Preece, Siân. 2019. Elite bilingual identities in higher education in the anglophone world: The stratification of linguistic diversity and reproduction of socio-economic inequalities in the multilingual student population. Journal of Multilingual and Multicultural Development 40(5). 404-420.

Qin, Yaqing. 2014. Continuity through change: Background knowledge and China's international strategy. The Chinese Journal of International Politics 7(3). 285-314.

Study International Staff. 2018. Which Country is home to the largest international student Population? Available at: https://www.studyinternational.com/news/country-homelargest-international-student-population/.

van der Walt, Crista. 2013. Multilingual higher education: Beyond english medium orientations. Buffalo, NY: Multilingual Matters.

Yun, Jianhui \& Zhu, Yaoshun. 2017. “一带一路”背景下云高校面向南亚东南亚留学生教育发展研 究[The study on the educational development of the international students from South Asia and Southeast Asia receiving higher education in Yunnan in the context of Belt and Road Initiative], 云南农业学学报 (社会科学). [Journal of Yunnan Agricultural University (Social Science)] 11(1). 97-101. https://kns.cnki.net/KCMS/detail/detail.aspx?dbcode=CJFD filename $=$ YNNS201701018.

Zhang, Jie \& Yuqin Wu. 2020. Providing multilingual logistics communication in COVID-19 disaster relief. Multilingua 39(5). 517-528.

Zhang, Jie. In preparation Language Policy and Planning for the Modern Olympic Games: China's Experiences. Boston/Berlin: De Gruyter Mouton. 